\title{
CUSTEIO BASEADO EM ATIVIDADES APLICADO À PRESTAÇÃO DE SERVIÇOS MÉDICOS DE RADIOLOGIA
}

\author{
Simeão Antônio Silveira Brasil \\ Professor Ms. do Depto. de Ciências Contábeis \\ do Centro Universitário La Salle - Canoas/RS \\ E-mail:simant@lasalle.tche.br
}

\section{RESUMO}

Este trabalho emprega o Método de Custeio por Atividades - Activity-based Costing - com o propósito de quantificar o custo unitário dos exames radiológicos produzidos no Setor de Radiologia Médica Convencional em uma Instituição de Saúde. Foram custeados 111 tipos de exames, sendo 27 realizados com o uso de substâncias médicas contrastantes e 84 exames convencionais, observando-se os atributos de consumo de filmes radiológicos de cada um. Os resultados do trabalho mostram que o $A B C$ propicia um bom nível de detalhamento das atividades selecionadas para a realização de exames radiológicos convencionais e com o uso de substâncias de contraste, visto que esses objetos foram agrupados segundo os atributos de consumo de filmes radiológicos.

Palavras-chave: Custeio por Atividades; Radiologia Médica Convencional; Exames Radiológicos.

\section{ABSTRACT}

This study uses the Activity-based Costing Method in order to quantify the unit cost of radiology exams realized at the Conventional Medical Radiology Sector of a Health Institution. We verified the cost of 111 types of examinations, 27 of which were carried out through contrast agents, while 84 were conventional exams, observing the radiology film consumption attributes of each type. Results show that the $A B C$ provides an adequate level of detail in relation to the activities selected for realizing conventional and contrast radiology exams, since these objects were grouped according to radiology film consumption attributes.

Keywords: Activity-based Costing; Conventional Medical Radiology; Radiology Exams. 


\section{INTRODUÇÃO}

Os hospitais e demais estabelecimentos congêneres são continuamente fiscalizados pelos órgãos públicos e por entidades das classes profissionais afins, no que diz respeito aos padrões de qualidade do atendimento e no pronto restabelecimento dos pacientes, devido à peculiaridade que têm de atender à saúde e à vida.

$\mathrm{O}$ atingimento das metas e objetivos que lhes garantam o nível de qualidade requerido obriga os gestores a implantarem processos de atendimento que permitam o rápido diagnóstico das patologias e a prescrição eficaz do respectivo tratamento. Um dos instrumentos que propicia essa eficácia é o de Diagnóstico por Imagens, o qual contempla diferentes métodos de exame e tecnologias variadas para gerar imagens da constituição esquelética do corpo humano e dos órgãos internos que o compõe. Nessa classificação, insere-se a Radiologia Médica Convencional, caracterizada por ter um amplo espectro funcional no apoio ao diagnóstico médico.

Sob outro aspecto, a evolução tecnológica na área da saúde tem sido uma constante, obrigando as instituições a acelerarem o ritmo de imobilizações de equipamentos médico-hospitalares, objetivando manterem-se competitivas através do incremento da qualidade dos serviços. Isso provoca mudanças constantes na estrutura de custos das organizações, tornando as informações tradicionais obsoletas e incorretas pela subjetividade que o rateio proporciona, principalmente naquelas em que os custos indiretos são significativos.

A principal justificativa para o emprego do Método ABC (Activity-based Costing) concentra-se nas características da estrutura de custos, sendo considerada apropriada a sua implementação em organizações que possuam níveis relevantes de custos indiretos (MARTINS, 2001). O mesmo autor afirma, ainda, que o Método $A B C$ permite apropriar os recursos segregados como custos indiretos aos objetos de custo através de bases objetivas, ou seja, por meio de medidas de saída reais, gerando informações mais acuradas em relação a esses objetos.

Assim, independentemente do porte e da estrutura de custos de uma instituição prestadora de serviços de radiologia médica convencional, a empregabilidade do $A B C$ no custeamento das atividades e dos objetos de custos delimita o problema de pesquisa deste trabalho.

\section{CUSTEIO POR ATIVIDADES}

Na visão da Teoria de Custos, o surgimento do Método $\mathrm{ABC}$ contribuiu para o preenchimento de uma lacuna informacional a que o Método Baseado em Volume ou VBC (Volume - based Costing) não satisfazia. Os gestores diante do avanço do nível competitivo mundial ansiavam por uma ferramenta de custos que contemplasse as modificações na estrutura de custos das empresas advindas da evolução tecnológica dos ativos fixos. A evolução do método atingiu as expectativas e tornou-se, num segundo momento, o esteio dos conceitos da Gestão Estratégica de Custos e de apoio à Gestão Baseada em Atividades, ou ABM (Activity - based Management), (MARTINS, 2001; NAKAGAWA, 2001). O ABC preceitua que as atividades consomem recursos e os produtos consomem atividades. Portanto, o consumo de recursos pode ser apropriado diretamente aos produtos através de medidas de saída. Essas medidas devem ser definidas através de uma minuciosa identificação do consumo de recursos por atividades relevantes e das atividades que são requeridas pelos produtos. Essa sistemática de apropriação dos custos aos objetos é chamada de rastreamento. $\mathrm{O}$ resultado do processo é a perfeita identificação do recurso consumido pelo produto obtido, mesmo sendo o recurso um custo indireto. Assim, pode-se afirmar que os recursos "fluem" pelas atividades e "incorporam-se" aos produtos.

A aplicabilidade dos conceitos do $A B C$ no custeio dos produtos e serviços das organizações é preconizada, também, pelos seguintes autores:

a) o $A B C$ permite aos gestores a antevisão dos processos e a determinação dos direcionadores de custos respectivos, e dessa forma, apoiando a elaboração da peça orçamentária (HORNGREN, 2000);

b) $\mathrm{ABC}$ induz mudanças no comportamento organizacional pela ampliação do foco de atenção para as atividades em detrimento dos volumes, concorrendo para a excelência (NAKAGAWA, 2001);

c) o rastreamento das atividades permite a análise dos processos e a identificação da 
causa-raiz daquelas que não agregam valor aos produtos e serviços, contribuindo para a eficiência do emprego de recursos e para a eficácia no atingimento das metas e objetivos (CHING, 2001);

d) $\mathrm{ABC}$ permite aos gestores compreender os fatos geradores de consumo de recursos (FALK, 2001);

e) a acurácia informacional relativa aos custos e o controle dos direcionadores de custos dão sustentação aos esforços para o atingimento de um custo-alvo planejado;

f) o ABC subsidia a avaliação da eficiência através do monitoramento dos direcionadores de custos (SCHMIDT, 2002);

g) $\mathrm{ABC}$ permite o gerenciamento da eficácia dos processos através do monitoramento das medidas de saída.

A acurácia advinda do Método ABC justifica o seu emprego como uma ferramenta adequada ao controle do custo unitário e ao planejamento e controle da estrutura dos custos totais.

Os direcionadores, por sua vez, contribuem para o controle da eficiência das atividades uma vez que o custo total flutuará na mesma razão da sua variação. O método permite ao gestor visualizar as atividades que não agreguem valor dentro de um processo produtivo, e também contribui para a avaliação do desempenho dos centros de atividades.

Conforme Nakagawa (2001, p.9):

Como espinha dorsal da ABM (Activity-based Management), o ABC vem sendo reconhecido como elemento indispensável à implementação com sucesso da Reengenharia de Processos, Gestão de Processo de Qualidade Total, decisões de investimentos em Tecnologias Avançadas de Produção, avaliação de desempenhos operacionais e econômicos que tornem a empresa de classe mundial (WCM).

Segundo Ching (2001), o ABC fornece ao gestor 4 escopos diferentes de gestão:

a) análise de linhas de produtos e serviços;

b) análise de clientes;

c) análise organizacional;

d) análise de processos de negócios.

O Sistema de Custeio por Atividades tem se caracterizado como uma importante ferramenta gerencial dada a sua capacidade de praticamente eliminar os rateios subjetivos e propiciar aos gestores uma visão das atividades que não agreguem valor.

Sobre o ABC, Nakagawa (2000, p.42) afirma:

Os sistemas tradicionais de custeio estão basicamente voltados para o cálculo e informação de custos históricos, mesmo que em moeda constante e, principalmente, para a avaliação de inventários, uma das etapas preparatórias para a elaboração das demonstrações contábeis.

\subsection{Direcionadores de Custos ou Cost-drivers}

A definição de direcionadores de custos é encontrada em várias obras e em diversos níveis de detalhamento. À luz do entendimento da pesquisa, é a expressão quantitativa através da qual se rastreiam os elementos de custos às atividades e dessas para os objetos. Fato Gerador, por sua vez, diz respeito à causa-raiz da atividade que irá produzir o efeito de consumir recursos.

Nakagawa (2001, P. 74) refere-se ao direcionador de custo como cost-driver e o define como "uma transação que determina a quantidade (não a duração) e, através dela o custo de uma atividade".

Sob o prisma analítico, o mesmo autor decompõe os direcionadores em dois tipos, cada um aplicável a uma fase do custeamento por atividades. Como o conceito central é o de que os recursos são consumidos pelas atividades e as atividades são requeridas pelos produtos, os direcionadores de custos são aplicados em dois estágios de custeamento, sendo os direcionadores de 1e estágio para a identificação da quantidade de recursos consumidos pelas atividades e, os direcionadores de $2^{\circ}$ estágio para a mensuração da quantidade de atividades requeridas pelos produtos.

Martins (2002, P. 39) cita que "cada elemento de custo de uma atividade deve ser expresso em termos de uma medida de volume pelo qual o elemento de custo varia mais diretamente".

Ching (2001, p. 94) define a medida de saída das atividades como sendo "o resultado ou produto de uma atividade, representado em termos de número de ocorrências da atividade por período".

Pode-se resumir, portanto, a definição de medida 
de saída como sendo o parâmetro através do qual se mede o consumo de atividades.

Os critérios que irão ser usados na avaliação e escolha dos direcionadores devem contemplar as relações de causa e efeito entre as atividades, os recursos e os produtos (MARTINS, 2002).

Conforme Horngren et al. (2000) a relação de causa e efeito pode ser determinada de diferentes modos:

a) pela relação física entre os custos e o direcionador de custos como, por exemplo, material direto e unidades produzidas;

b) em razão de acordo contratual como, por exemplo, o número de minutos-telefone e o custo da linha telefônica, e

c) pelo conhecimento implícito estabelecido pela coerência e o conhecimento das operações.

Os autores supra (2000, p. 238) limitam o uso de planilhas de correlação na determinação dos direcionadores e alertam que podem ocorrer falhas na sua determinação. "Somente uma verdadeira relação de causa e efeito, não uma simples correlação, estabelece uma relação economicamente plausível entre os custos e seus respectivos direcionadores".

Nakagawa (2001, p. 75-76) lista os seguintes critérios para a seleção dos direcionadores:

a) facilidade/dificuldade de coletar os dados relativos aos cost-drivers, porque os custos de mensuração juntamente com os custos associados às essas decisões determinam o sistema ótimo de custeio $A B C$;

b) grau de correlação com o consumo de recursos, o qual, em termos estatísticos, deve aproximar-se de 1 ;

c) efeitos comportamentais, que é o critério que oferece o maior grau de risco na escolha de cost-drivers.

\subsection{Análise das Atividades}

Ching (2001, pp.85-108) sugere que a implementação do ABC seja concebida através da aplicação de um modelo composto de 4 blocos.

No primeiro bloco são feitos o levantamento das atividades, o cálculo do custo de cada uma e a determinação da medida de saída. A seguir, o segundo bloco contempla a identificação dos objetos de custos que requerem as atividades. No terceiro bloco é feita a classificação das atividades agregadoras de valor, não agregadoras de valor e secundárias, sendo que esta última é definida como sendo a que dá apoio às demais, independentemente de que sejam agregadoras de valor ou não, e que não sejam eliminadas. Por fim, no quarto bloco, é determinada a causa que originou cada atividade.

A implantação do $A B C$ segue o seguinte roteiro:

a) definição do escopo de análise, em que a extensão da aplicação do método é delimitada considerando o grau de representatividade que o consumo de recursos para esse fim terá em relação à disponibilidade de recursos da empresa, bem como os objetivos estratégicos que foram planejados;

b) criação de um mapa de atividades de modo que se possa visualizar as atividades. Para isso, é necessária a identificação de elementos-chave, ou seja, aqueles que possuam um conhecimento profundo e detalhado das atividades que serão custeadas. Após isso, as atividades são codificadas em forma de um dicionário com o propósito de não deixar dúvidas quanto ao significado que têm nos processos estudados;

Nessa fase, algumas considerações são evidenciadas pelo autor:

- Deve existir somente uma medida de saída por atividade;

- Podem-se agrupar as atividades com alto grau de correlação;

- Devem-se focar $20 \%$ das atividades que representem $80 \%$ do consumo de recursos;

- O número de atividades devem situar-se na faixa de 6 a 8 por área.

c) definição das medidas de saída das atividades através da seleção das medidas e determinação da freqüência de sua ocorrência.

\section{MÉTODO DE PESQUISA}

A questão da pesquisa converge os esforços do trabalho no sentido de propor um modelo de custeamento dos objetos de custos produzidos no Setor de Radiologia Médica Convencional de um hospital.

Segundo Tobar e Yalour (2001), os critérios básicos, na escolha do tipo de pesquisa, apoiam-se 
na relação que têm aos seus fins e meios. A investigação e análise do fenômeno, no campo de pesquisa, estão em processo de curso, em seu meio natural. Assim, o método de pesquisa deve contemplar um conjunto de técnicas que se adaptem a essa natureza.

Conforme Hoppen et al.(1996, p. 2), o método de pesquisa qualitativa constitui-se num "[...] conjunto de métodos e técnicas mais adaptadas à natureza dos dados".

Os mesmos autores identificam três métodos de pesquisa qualitativa: a observação participante, a pesquisa-ação e o estudo de caso. Na observação participante, o pesquisador não manipula as variáveis contidas nos fenômenos, mas, tão somente, deve assumir uma posição passiva ante eles. Na pesquisa-ação, o pesquisador envolve-se, ativa e concomitantemente, à realização da análise dos fenômenos. $O$ estudo de caso examina o fenômeno a partir do emprego de instrumentos de coleta diversificados e em fontes variadas de modo a focalizar os fenômenos no tempo.

O estudo de caso é o tipo de pesquisa circunscrita a poucas unidades de análise, entendidas essas como: pessoas, famílias, produtos, instituições, comunidades, regiões e países. Por isso, a riqueza dos resultados não está na extensão, mas na profundidade des- se tipo de pesquisa (TOBAR; YALOUR, 2001). Considerando o objetivo principal do estudo, o custeio dos exames radiológicos realizados no ano 2002, a pesquisa pretende coletar dados reais, não hipotéticos, a fim de que possa confrontar a conceituação teórica com um processo de serviços já ocorrido. Diante do exposto, o trabalho optará pela realização de uma pesquisa do tipo qualitativa, empregando os conceitos e técnicas pertinentes ao método de um estudo de caso.

Assim, a pesquisa apontará as ferramentas de coleta para as áreas de apoio e operacionais da radiologia médica convencional, aos registros contábeis e documentos de controle interno inerentes às atividades objeto do estudo, e à identificação e aplicação de entrevistas semiestruturadas com elementos-chave envolvidos no processo.

\section{ESTUDO DE CASO}

$\mathrm{O} A B C$ requer o desenho dos processos que serão estudados para, a seguir, listá-los na forma de um dicionário como forma de tornar inequívoca a interpretação dos atributos de cada atividade. A FIG. 1 mostra as atividades que são desenvolvidas no Setor de Radiologia Médica.

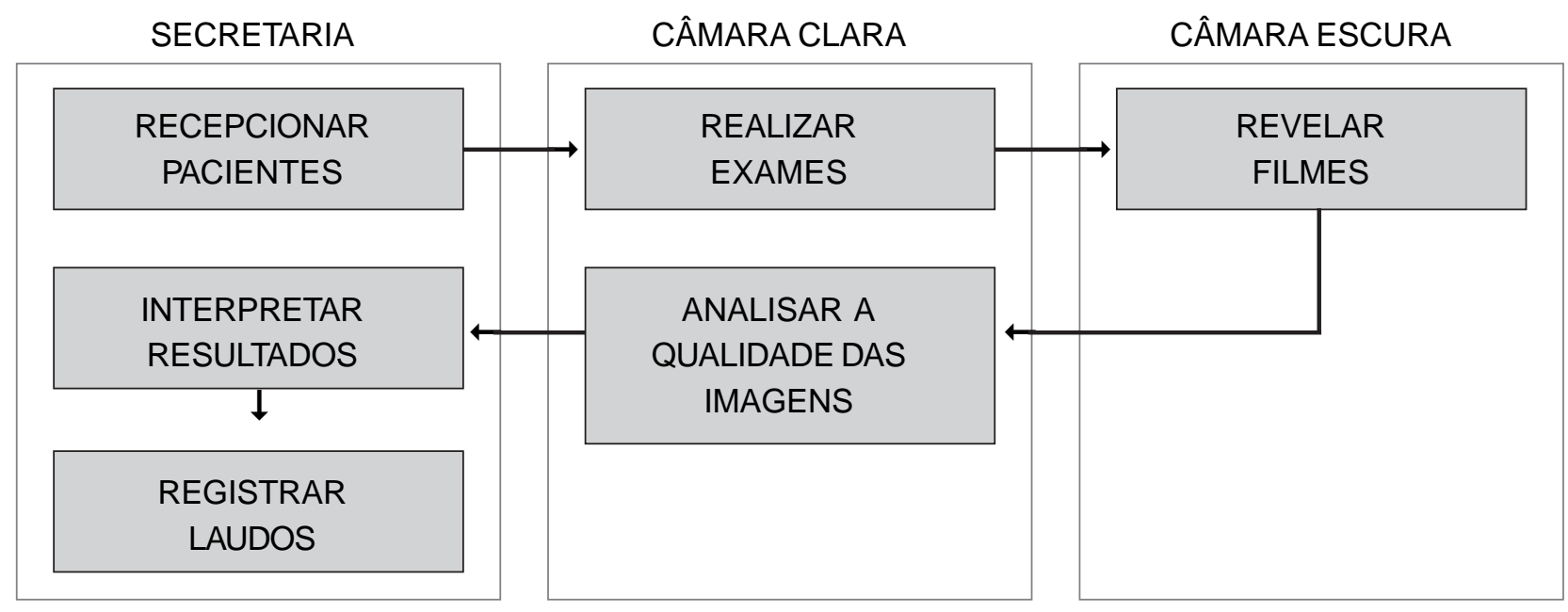

Figura 1 - Mapa de Atividades da Radiologia Médica Convencional.

\section{1 - Dicionário das Atividades Relevantes}

Na contextualização do dicionário, a pesquisa nomeou o Setor Administrativo como Setor de Apoio, estando contidos nele, os subcentros de atividades onde se realizam os processos de Recepção de Pacientes, Interpretação de Resultados e Registro dos Laudos. OSetor Operacional, por sua vez, recebe o nome de Setor Técnico, como já é conhecido pela comunidade hospitalar, decomposto em subcentros de atividades onde são executadas as atividades de Realizar Exames Convencionais, Realizar Exames Contrastados e Revelar Filmes Radiológicos. 
A atividade Analisar Imagens não requer grande consumo de recursos. A sua representatividade em relação aos custos totais montou em $1.6 \%$, pois é acessória às atividades de realizar exames convencionais e contrastados. Todavia, essa atividade consta no Mapa de Atividades porque é essencial ao processo como um todo, pois, se uma imagem não apresentar os atributos que a qualifiquem como proveitosa à formação da convicção dos médicos radiologistas, deve ser repetida, gerando, assim, outro processo de realização de incidências radiológicas. Esse retrabalho, contudo, foge do escopo do estudo e não será abordado. Sob a ótica da pesquisa, a sua expressão deve ser considerada como uma despesa.

Segundo o que foi explicitado anteriormente, no que concerne à divisão do Setor de Radiologia Médica Convencional, conforme os critérios da Instituição
Hospitalar é mostrado em cada quadro do dicionário o setor onde são desenvolvidas as respectivas atividades consideradas relevantes. A seguir, são definidos os locais onde são desenvolvidas as atividades segundo a ótica do $A B C$, conceituados como subcentros de atividades. Em seguida, são mostradas as tarefas que compõem as atividades rastreadas e os recursos consumidos em cada uma delas. Em continuidade, o dicionário mostra os inputs e outputs dos processos, bem como as medidas de saída de cada atividade. Por fim, segue, no item Definição, a descrição analítica das tarefas e funções que compõem cada atividade relevante, às vezes com observações julgadas necessárias à compreensão do que se pretende apresentar.

As atividades consideradas relevantes que compõem o processo de produzir imagens radiológicas são listadas no Dicionário das Atividades, a seguir.

\footnotetext{
Dicionário de Atividades Radiologia Médica

Setor: Apoio

Sub-Centro de Atividades: Secretaria

Tarefas: Identificar e cadastrar os pacientes. Preencher a requisição de exame. Instruir os pacientes.

Recursos: Mão-de-Obra Administrativa/ Energia Elétrica/ Depreciação

In Put: Requisição Médica para realizar Exame Radiológico

Out Put: Requisição de Exame Radiológico

Medida de Saída: Número de Pacientes

Definição: A recepcionista identifica o paciente ou o seu responsável. Compara a requisição médica com a identidade do paciente e o documento que comprova o convênio, caso não seja particular. Preenche o Livro de registro e emite a requisição de exame com o respectivo número de ordem de registro. A seguir, o exame é agendado. Caso o exame seja do tipo contrastado, o paciente ou responsável recebe instruções dietéticas e tem seu exame agendado. Isso se deve a que as vias digestivas, ou se for o caso, as vias urinárias ou venosas, são preenchidas com substâncias contrastantes quando da realização das incidências de modo que possam ser visualizadas radiologicamente.
}

\section{Quadro 1 - Atividade Recepcionar Pacientes}

\begin{tabular}{l} 
Dicionário de Atividades Radiologia Médica \\
Setor: Técnico \\
\hline Sub-Centro de Atividades: Câmara Clara \\
\hline Tarefas: Preparar o exame e realizar as incidências \\
\hline Recursos: Mão-de-Obra Técnica/ Depreciação / Energia Elétrica / Filmes Radiológicos \\
\hline In Put: Requisição de Exame Radiológico \\
\hline Out Put: Imagens Radiológicas \\
\hline Medida de Saída: Número de Exames Convencionais \\
\hline Definição: O técnico em radiologia, após examinar a requisição de exame apresentada pelo seu condutor ou acompanhante, \\
seleciona os chassis colocando nesse a identificação do exame e do técnico. Conduz o paciente para a sala de exames. \\
Posiciona o paciente para executar a incidência. Sai da sala de exames, vai até o painel de controle do equipamento de Raios- \\
X e seleciona os fatores de exposição. Executa a incidência e reposiciona o paciente.
\end{tabular}

\section{Quadro 2 - Atividade Realizar Exame Convencional}




\begin{tabular}{l} 
Dicionário de Atividades Radiologia Médica \\
Setor: Técnico \\
\hline Sub-Centro de Atividades: Câmara Clara \\
\hline Recursos: Mão-de-Obra Técnica/ Depreciação / Energia Elétrica / Material Médico / Medicamentos \\
\hline In Put: Requisição de Exame \\
\hline Out Put: Imagens Radiológicas \\
\hline Medida de Saída: Número de Exames Contrastados \\
\hline Definição: O técnico em radiologia, após examinar a requisição de exame apresentado pelo paciente ou seu acompanhante, \\
executa a anamnese e a entrevista do paciente para certificar-se de que foram cumpridas as instruções dietéticas. A seguir, \\
instrui o paciente a colocar o avental para exames, seleciona os chassis colocando nesse a identificação do exame e do técnico \\
e conduz o paciente para a sala de exames. Injeta a substância de contraste à base de lodo para que esta preencha as vias \\
urinárias do paciente. Se for exame das vias digestivas injeta Sulfato de Bário ou o paciente ingere composto contrastante. \\
Posiciona o paciente para executar as incidências. Seleciona os fatores de exposição e executa a incidência. Reposiciona o \\
paciente para outra incidência e repete a operação. Ao final das incidências, os chassis são colocados no escaninho da Câmara \\
Escura para serem revelados. Após a revelação, o técnico avalia as imagens. Se forem reprovadas, repete as incidências. Caso \\
sejam aprovadas, retira a Pinça de Knutson da uretra do paciente e o libera.
\end{tabular}

\section{Quadro 3 - Atividade Realizar Exames Contrastados}

\begin{tabular}{l} 
Dicionário das Atividades Radiologia Médica \\
Setor: Técnico \\
\hline Sub-Centro de Atividades: Câmara Escura \\
\hline Tarefas: Retirar filmes dos chassis e colocá-los na processadora. Realimentar os chassis com filmes e colocá-los no escaninho. \\
\hline Recursos: Mão-de-Obra Técnica/ Depreciação / Energia Elétrica / Composto Revelador \\
\hline In Put: Número de Chassis \\
\hline Out Put: Películas Reveladas \\
\hline Out Put: Número de Imagens \\
\hline Medida de Saída: Número de Exames \\
\hline Definição: O Técnico de Câmara Escura recolhe os chassis no escaninho. Retira as películas dos chassis e as coloca na \\
processadora. A seguir, alimenta os chassis vazios com novos filmes e os coloca no escaninho para que sejam recolhidos pelos \\
técnicos na Câmara Clara para novo uso.
\end{tabular}

\section{Quadro 4 - Atividade Revelar Filmes}

\begin{tabular}{l} 
Dicionário das Atividades Radiologia Médica \\
Setor: Técnico \\
\hline Subcentro de Atividades: Câmara Clara \\
\hline Tarefas: Colocar as películas reveladas no Negatoscópio e avaliar a qualidade da imagem. \\
\hline Recursos: Mão-de-Obra Técnica/ Depreciação / Energia Elétrica. Agrupados na atividade Realizar Exames Convencionais. \\
\hline In Put: Películas Reveladas \\
\hline Out Put: Exames Avaliados \\
\hline Medida de Saída: Número de Incidências \\
\hline Definição: O técnico em radiologia aguarda a revelação dos filmes com o número do exame e as suas iniciais fixadas na película. \\
Os filmes revelados são pegos na saída da processadora. De posse das películas correspondentes aos exames que realizou, \\
o técnico as coloca no negatoscópio. Este equipamento contém uma luz fluorescente no seu interior e permite que a luminosidade \\
passe através de uma chapa acrílica especial sobre a qual são colocadas as películas a serem examinadas. Assim, as partes \\
do corpo humano que foram radiografadas salientam-se pelo contraste que é apurado pela luminosidade, permitindo, então, que \\
a imagem possa ser avaliada minuciosamente.Observação: Atividade acessória às atividades relevantes.
\end{tabular}

Quadro 5 - Atividade Analisar a Qualidade da Imagem de Exames Convencionais e Contrastados 


\section{Dicionário das Atividades Radiologia Médica}

Setor: Apoio

Centro de Atividades: Laudo Médico

Tarefas: Colocar as imagens no negatoscópio e interpretar os resultados. Gravar o laudo em fita cassete.

Recursos: Serviços de Pessoa Jurídica / Energia Elétrica / Depreciação

In Put: Imagens Radiológicas

Out Put: Laudos médicos gravados em fita cassete

Medida de Saída: Número de Laudos

Definição: O médico radiologista coloca as películas referentes ao exame que será laudado no negatoscópio. Interpreta as imagens e grava verbalmente o laudo em fita cassete para que sejam transcritas e digitadas.

\section{Quadro 6 - Atividade Interpretar Resultados}

\begin{tabular}{l} 
Dicionário das Atividades Radiologia Médica \\
Setor: Apoio \\
\hline Centro de Atividades: Digitação \\
\hline Tarefas: Transcrever o laudo médico do exame gravado em fita cassete e digitar a transcrição. Imprimir o laudo e juntar às \\
películas respectivas. \\
\hline Recursos: Mão-de-Obra Administrativa/ Depreciação/ Energia Elétrica/ Material de Expediente \\
\hline In Put: Laudos médicos gravados em fita cassete \\
\hline Out Put: Laudos médicos imprimidos \\
\hline Medida de Saída: Número de Exames \\
\hline Definição: O digitador colocar fones de ouvido para ouvir o laudo gravado pelo médico radiologista, enquanto digita a transcrição \\
no computador. Após, imprime o laudo e anexa-o às películas do exame respectivo.
\end{tabular}

\section{Quadro 7 - Atividade Registrar Laudos}

\section{2 - Direcionadores Percentuais Agrupadores dos Recursos}

Dentre os recursos consumidos, consta o material médico. Esses são referentes ao montante de débitos na aquisição dos filmes radiológicos usados nos exames, e às substâncias para formar o composto químico que é utilizado pela processadora no processo de revelar e fixar as imagens radiológicas nas películas. A medida indexadora dos filmes é em centímetros quadrados, pois a superfície ${ }^{1}$ dos mesmos varia de $234 \mathrm{~cm}^{2}$ a $1.505 \mathrm{~cm}^{2}$. No entanto, os filmes são indexados pelo fornecedor em metros quadrados. O consumo de material direto, então, será determinado em função do número de incidências e do tamanho dos filmes usados em cada tipo de exame. O agrupamento dos custos às atividades Realizar Exames Convencionais e Realizar Exames Contrastados passou por um tratamento específico, pois cada exame possui um custo a ser rastreado segundo o que consome de filmes radiológicos, ou seja, de acordo com o número de incidências de cada exame e o tamanho dos filmes utilizados em cada incidência.
Dessa forma, o trabalho utilizou um direcionador percentual como forma de agrupar o consumo de recursos pelas atividades relativas aos respectivos exames. Esse tratamento matemático, assim, contemplou a divisão do consumo de filmes dos diferentes exames sem prejuízo da exatidão do consumo de filmes radiológicos de cada grupo de exames, uma vez que, para cada agrupamento de consumo de filmes, fora aplicado um direcionador de recurso.

No período estudado, foram realizados 94.589 exames, sendo 93.122 convencionais e 1.467 contrastados. Todos os recursos foram agrupados segundo os centros onde são desenvolvidas as atividades relevantes. Portanto, os direcionadores do recurso são $98,4491 \%$ a serem alocados à atividade Realizar Exames Convencionais e 1,5509\% à atividade Realizar Exames Contrastados. Os recursos, depois de agrupados pelos direcionadores percentuais, serão rastreados para as atividades.

Como o consumo do recurso desse material é direto e variável em relação a cada grupo de objetos de custo, ou seja, os diferentes tipos de exames, contrastados ou convencionais, o trabalho

${ }^{1}$ As medidas dos filmes radiológicas são fornecidas em centímetros, sendo eles em 13x18, 18x24, 15x40, 24x30, 35x35 e 35x43. 
rastreará para as atividades os recursos de modo a que se possa contemplar os exames convencionais e contrastados diferentemente, relacionando a cada tipo de exame os atributos de consumo de filme radiológico de cada um.

Assim, as parcelas respectivas do custo com filmes radiológicos serão antes alocadas às atividades de realizar exames, por grupo de exames que requeiram a mesma quantidade de filme radiológico. Depois, as atividades serão rastreadas para os objetos.

Os consumos de filmes radiológicos por tipo de exame contrastado são mostrados a seguir:

\section{Tabela 1 - Consumo de Filmes Radiológicos por Grupo de Exame e Atividade Relevante.}

\begin{tabular}{l|r}
\hline Atividade & Consumo \\
Realizar Exame Contrastado & $\mathrm{R} \$ 1.624,38$ \\
\hline Realizar Exame Convencional & $\mathrm{R} \$ 32.791,23$ \\
\hline Total por Atividade & $\mathbf{R} \$ \mathbf{3 4 . 4 1 5 , 6 1}$ \\
\hline
\end{tabular}

\subsection{Direcionadores de Recursos}

Conforme Weygandt et al. (2001), na 1a fase as despesas gerais são distribuídas em grupos de custos por atividade, não por departamentos, sendo cada grupo de custos correspondente a um tipo de atividade. $\mathrm{Na} 2^{\text {a }}$ fase, as despesas gerais são distribuídas aos grupos de custos por atividades através de uma variável de custos (direcionador de recursos), que mede o número de atividades individuais realizadas.

Para a aplicação do ABC no Setor de Radiologia Médica Convencional, primeiramente foi preciso considerar os seguintes aspectos:

a) os objetos de custo são diversos. Somam 111 tipos entre convencionais e com o uso de substâncias de contraste, ou exames contrastados;

b) os objetos de custo por tipo, ou seja, os exames contrastados e exames convencionais, requerem, em igual intensidade, as atividades Recepcionar Pacientes, Revelar Filmes, Interpretar Resultados e Registrar Laudos;

c) o direcionador tempo é de difícil emprego para as atividades de realizar exames porquanto não se pode estabelecer um tempo de atendi- mento padronizado para a realização de cada exame. Isso se dá porque o tempo de atendimento depende da idade do paciente, das condições patológicas, da necessidade de ser conduzido ou não e do número de incidências em cada exame. Caso fossem estabelecidos padrões-tempo para a execução de tarefas na área da saúde, poder-se-ia mediar a qualidade dos serviços para baixo, colocando, assim, em risco a integridade dos pacientes;

d) na Câmara Clara são realizados os exames convencionais e os que requerem o uso de substâncias de contraste e de medicamentos, sendo que esses exames consomem a mesma mão-de-obra, tanto a direta como a indireta.

Ante o exposto, a pesquisa utilizou os seguintes direcionadores:

- Para a atividade Recepcionar Pacientes utilizou-se o número de pacientes atendidos em 2002, 86.687 pacientes.

- Para a atividade Revelar Filmes considerou-se o número de incidências havidas em todos os exames, pois é a medida efetiva de consumo dessa atividade, ou seja, 214.315 incidências. Esse direcionador é o resultado do produto do número dos diferentes tipos de exames pela quantidade de incidências respectivas, e a soma da quantidade de exames realizados.

- Para a atividade Interpretar Resultados considerou-se o número de exames, porquanto a cada exame é apensado um laudo independentemente da quantidade de incidências.

- Para a atividade Registrar Laudos foi utilizado o número de laudos registrados, cujo valor é igual ao número de exames, ou seja, 94.589 laudos.

- Para as atividades Realizar Exames Convencionais e Realizar Exames Contrastados a medida de saída utilizada foi número desses exames por ser o parâmetro que melhor expressa o consumo de recursos.

Dada a quantidade de exames, como dito anteriormente, a apropriação direta é de difícil consecução. Logo, serão rastreados.

Os custos segregados por elementos de custos e por atividades são mostrados na Tab. 2. 
Tabela 2 - Elementos de Custos na Radiologia Médica Convencional

\begin{tabular}{|c|c|c|c|c|c|c|c|}
\hline $\begin{array}{l}\text { Atividades } \\
\text { Elementos de custos }\end{array}$ & $\begin{array}{r}\text { Material de } \\
\text { Limpeza e } \\
\text { Higiene }\end{array}$ & Depreciação & Energia & $\begin{array}{l}\text { Material } \\
\text { Médico }\end{array}$ & Revelador & $\begin{array}{l}\text { Medica- } \\
\text { mentos }\end{array}$ & $\begin{array}{l}\text { M.D.O } \\
\text { Técnica }\end{array}$ \\
\hline Recepcionar Pacientes & & $2.386,95$ & 547,61 & - & - & - & \\
\hline Realizar Exames Convencionais & 771,41 & $18.371,72$ & 976,34 & $32.791,23$ & - & 275,22 & $173.111,29$ \\
\hline Realizar Exames Contrastados & 12,15 & 281,64 & 14,96 & $1.624,38$ & - & $6.313,48$ & $2.727,26$ \\
\hline Revelar Filmes & & $4.903,32$ & $1.255,87$ & - & $308.857,20$ & - & $37.027,20$ \\
\hline Interpretar Resultados & - & 995,33 & 642,15 & - & - & - & 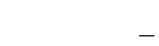 \\
\hline Registrar Laudos & & $1.595,00$ & 942,77 & - & - & - & \\
\hline Total por Elementos de Custos & 783,56 & $28.533,98$ & $4.379,70$ & $34.415,61$ & $308.857,20$ & $6.588,70$ & $212.865,75$ \\
\hline $\begin{array}{l}\text { Atividades } \\
\text { Elementos de custos }\end{array}$ & & $\begin{array}{c}\text { M.D.O } \\
\text { Administrativa. }\end{array}$ & $\begin{array}{r}\text { Serviços de } \\
\text { Pessoa } \\
\text { Jurídica }\end{array}$ & $\begin{array}{r}\text { Manu- } \\
\text { tenção }\end{array}$ & $\begin{array}{l}\text { Material de } \\
\text { Expediente }\end{array}$ & $\begin{array}{r}\text { Outras } \\
\text { Despesas }\end{array}$ & $\begin{array}{r}\text { Total por } \\
\text { Atividades }\end{array}$ \\
\hline Recepcionar Pacientes & & $8.137,15$ & & & $3.314,51$ & - & $14.386,22$ \\
\hline Realizar Exames Convencionais & & _ & & $20.492,89$ & - & - & $246.790,04$ \\
\hline Realizar Exames Contrastados & & - & & 322,85 & - & - & $11.296,72$ \\
\hline Revelar Filmes & & - & - & - & - & - & $352.043,59$ \\
\hline Interpretar Resultados & & - & $183.018,34$ & & - & _ & $184.655,82$ \\
\hline Registrar Laudos & & $24.411,45$ & & - & - & $1.152,00$ & $34.731,23$ \\
\hline Total por Elementos de Custos & & $32.548,60$ & $183.018,34$ & $20.815,74$ & $3.314,51$ & $1.152,00$ & $837.273,67$ \\
\hline
\end{tabular}

\section{3 - Custeio das Atividades Relevantes}

O método utilizado observou os seguintes aspectos:

No período estudado, foram realizados 93.122 exames convencionais e 1.467 exames contrastados, num total de 94.589 exames, sendo que dentro desses grupos de exames, estão contidos os diferentes tipos e os respectivos atributos de consumo.

Assim, a cada tipo de exame a pesquisa considerou o que se segue:

a) os exames têm atributos de consumo, ou seja, cada exame consome determinada quantidade de filme radiológico, como dito anteriormente;

b) as atividades de realizar exames consomem recursos das atividades de recepcionar pacientes, revelar filmes, interpretar resultados e registrar laudos. Logo, essas atividades são consumidas por todos os tipos de exames;

c) os exames contrastados consomem recursos da recepção em intensidade diferente dos exames convencionais. Isto se dá porque os pacientes recebem instruções de preparação nutricional e, por conseguinte, têm os exa- mes agendados. Portanto, são recepcionados novamente na data agendada. Assim, os exames contrastados consomem duplamente a atividade Recepcionar Pacientes.

Isso posto, a pesquisa conclui que, se o custo da medida de saída das atividades realizar exames convencionais e contrastados fosse rastreado para as atividades, a informação sobre o custo unitário seria distorcida. A causa dessa assimetria se daria pela transferência do custo dos filmes radiológicos aos objetos de custo sem considerar que cada um dos exames possui atributos de consumo diferenciados. Considerando isso, o trabaIho identificou um direcionador que representasse a causa do consumo de filmes radiológicos, de forma que pudesse alocar os recursos às atividades Realizar Exame Contrastados e Realizar Exames Convencionais de maneira mais real, considerando os atributos de consumo antes descritos.

Portanto, o custo rastreado será apropriado aos objetos pelo somatório do custo de cada atividade, segundo a quantidade que cada objeto requereu dessas atividades, sendo essas segregadas em exames convencionais e exames contrastados, e considerando os atributos de consumo de cada exame dentro dos grupos respectivos e de 
acordo com os objetos de custo segregados.

Uma exemplificação da sistemática empregada é, a seguir, mostrada.

Para um exame contrastado do tipo Clister Opaco são utilizadas 4 filmes com as medidas $35 \times 43$, e 6 filmes com as medidas $24 \times 30$.

Calculando a superfície total tem-se:

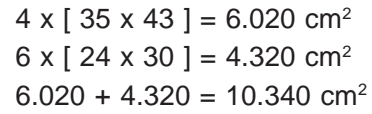

Portanto, a superfície total consumida no exame corresponde à soma das áreas dos tipos de filmes usados nesse exame.

Os preços unitários dos filmes radiológicos correspondentes em metros quadrados são:

$R \$ 0,38945$ para o filme de $35 \times 43$, e $R \$ 0,08813$ para o filme de $24 \times 30$.

Logo o consumo em unidades monetárias é:

$$
[4 \times 0,38945]+[6 \times 0,08813]=R \$ 2,0866
$$

Tabela 3 - Custo Unitário dos Filmes Radiológicos

\begin{tabular}{c|c|c|c|c}
\hline Medida do Filme & Área em $\mathbf{~ c m}^{2}$ & Área em $\mathbf{~ m}^{2}$ & Preço Unitário por $\mathbf{m}^{2}$ & Custo Unitário do Filme \\
\hline $13 \times 18$ & 234 & 0,02340 & $\mathrm{R} \$ 0,40$ & $\mathrm{R} \$ 0,00931$ \\
\hline $18 \times 24$ & 432 & 0,04320 & $\mathrm{R} \$ 0,73$ & $\mathrm{R} \$ 0,03173$ \\
\hline $15 \times 40$ & 600 & 0,06000 & $\mathrm{R} \$ 1,02$ & $\mathrm{R} \$ 0,06120$ \\
\hline $24 \times 30$ & 720 & 0,07200 & $\mathrm{R} \$ 1,22$ & $\mathrm{R} \$ 0,08813$ \\
\hline $30 \times 40$ & 1200 & 0,12000 & $\mathrm{R} \$ 2,04$ & $\mathrm{R} \$ 0,24480$ \\
\hline $35 \times 35$ & 1225 & 0,12250 & $\mathrm{R} \$ 2,13$ & $\mathrm{R} \$ 0,38945$ \\
\hline $35 \times 43$ & 1505 & 0,15050 & $\mathrm{R} \$ 2,59$ & \\
\hline
\end{tabular}

$\mathrm{Na}$ Tab. 4 estão relacionados os consumos e as quantidades de recursos respectivas, sendo que o total de exames com esses atributos de consumo foi de 500 .

Utilizando-se um direcionador percentual em relação ao total de exames contrastados, tem-se:

$$
[100 \times[500 / 1467]]=34,08316 \%
$$

$\mathrm{Na}$ Tab. 3, observa-se que o consumo de filmes radiológicos foi de $\mathrm{R} \$ 1.624,38$.

Aplicando-se o direcionador para obter o valor a ser alocado à atividade de Realizar Exame Contrastado do tipo Clister Opaco, fez-se:

$$
[34,08316 \% / 100] \times 1.624,38=R \$ 553,64
$$

Assim, o trabalho segregou e agrupou os recursos através de um direcionador que representasse o consumo efetivo, segundo os atributos de cada exame contrastado.

Os demais recursos agrupados na atividade Realizar Exames Contrastados, como mostrado na Tab. 4, foram calculados pela diferença entre o seu total, ou, $\mathrm{R} \$ 11.296,72$ e o custo com os filmes radiológicos anteriormente agrupados a essa atividade, ou, $R \$ 1.624,38$.
Esse valor montou em $\mathrm{R} \$ 9.672,34$ e foi alocado à atividade descrita aplicando-se o mesmo direcionador, conforme demonstrado abaixo.

$[34,08316 \% / 100] \times 9.672,34=R \$ 3.296,63$

Alocando o valor relativo ao consumo de material direto e a parcela de recursos comum a todos os exames contrastados, tem-se:

$1.045,00+3.296,63=R \$ 4.341,63$

Em conclusão, conforme o exemplo, $\mathrm{R} \$ 4.341,63$ é o montante de recursos agrupados à atividade Realizar Exames Contrastados do tipo Clister Opaco que será rastreado para essa atividade.

O mesmo método foi aplicado aos demais exames contrastados e aos exames convencionais como mostrado nas Tabelas 4 e 5. Após, os custos são rastreados para as atividades utilizandose os direcionadores de $1^{\circ}$ estágio, ou seja, a medida de atividade que melhor representa o consumo de recursos de cada grupo e exames convencionais e contrastados segundo os atributos de consumo de cada um. 
Tabela 4 - Recursos Agrupados à Atividade Realizar Exames Contrastados por Atributos de Consumo de Filmes Radiológicos

\begin{tabular}{|c|c|c|c|c|c|}
\hline $\begin{array}{c}\text { Grupos de Consumo } \\
\text { de Filme Radiológico } \\
\text { por Quantidades } \\
\text { em } \mathrm{cm}^{2}\end{array}$ & $\begin{array}{l}\text { Grupos de Consumo } \\
\text { de Filme Radiológico } \\
\text { em Unidades } \\
\text { Monetárias }\end{array}$ & $\begin{array}{c}\text { Número } \\
\text { de Exames } \\
\text { Realizados por } \\
\text { Grupos de Consumo }\end{array}$ & Direcionador & $\begin{array}{c}\text { Custos da } \\
\text { Atividade } \\
\text { Realizar Exames } \\
\text { Contrastados } \\
\text { Alocados aos } \\
\text { Grupos de Consumo }\end{array}$ & $\begin{array}{l}\text { Custos Segregados } \\
\text { por Grupos de } \\
\text { Consumo de } \\
\text { Filmes Radiológicos }\end{array}$ \\
\hline 10340 & $R \$ 1.045,00$ & 500 & $34,08 \%$ & $R \$ 3.296,64$ & $\mathrm{R} \$ 4.341,64$ \\
\hline 7525 & $\mathrm{R} \$ 5,85$ & 3 & $0,20 \%$ & $\mathrm{R} \$ 19,78$ & $\mathrm{R} \$ 25,63$ \\
\hline 6000 & $\mathrm{R} \$ 56,12$ & 46 & $3,14 \%$ & $\mathrm{R} \$ 303,29$ & $\mathrm{R} \$ 359,41$ \\
\hline 5472 & $\mathrm{R} \$ 235,98$ & 437 & $29,79 \%$ & $\mathrm{R} \$ 2.881,26$ & $\mathrm{R} \$ 3.117,24$ \\
\hline 5170 & $\mathrm{R} \$ 44,72$ & 43 & $2,93 \%$ & $\mathrm{R} \$ 283,51$ & $\mathrm{R} \$ 328,23$ \\
\hline 4560 & $\mathrm{R} \$ 69,75$ & 93 & $6,34 \%$ & $\mathrm{R} \$ 613,18$ & $\mathrm{R} \$ 682,93$ \\
\hline 4385 & $\mathrm{R} \$ 0,74$ & 1 & $0,07 \%$ & $\mathrm{R} \$ 6,59$ & $\mathrm{R} \$ 7,33$ \\
\hline 3010 & $\mathrm{R} \$ 133,36$ & 171 & $11,66 \%$ & $\mathrm{R} \$ 1.127,45$ & $\mathrm{R} \$ 1.260,81$ \\
\hline 2250 & $\mathrm{R} \$ 0,19$ & 1 & $0,07 \%$ & $\mathrm{R} \$ 6,59$ & $\mathrm{R} \$ 6,78$ \\
\hline 2160 & $\mathrm{R} \$ 25,74$ & 99 & $6,75 \%$ & $\mathrm{R} \$ 652,73$ & $\mathrm{R} \$ 678,47$ \\
\hline 2105 & $\mathrm{R} \$ 0,45$ & 1 & $0,07 \%$ & $\mathrm{R} \$ 6,59$ & $\mathrm{R} \$ 7,04$ \\
\hline 1566 & $\mathrm{R} \$ 6,48$ & 72 & $4,91 \%$ & $\mathrm{R} \$ 474,72$ & $\mathrm{R} \$ 481,20$ \\
\hline Totais & R\$ 1.624,38 & 1467 & $100,00 \%$ & R\$ 9.672,34 & $\mathrm{R} \$ 11.296,72$ \\
\hline
\end{tabular}

Tabela 5 - Recursos Agrupados à Atividade Realizar Exames Convencionais por Atributos de Consumo de Filmes Radiológicos

\begin{tabular}{|c|c|c|c|c|c|}
\hline $\begin{array}{c}\text { Grupos de Consumo } \\
\text { de Filme Radiológico } \\
\text { por Quantidades } \\
\text { em cm² }\end{array}$ & $\begin{array}{c}\text { Grupos de Consumo } \\
\text { de Filme Radiológico } \\
\text { em Unidades } \\
\text { Monetárias }\end{array}$ & $\begin{array}{c}\text { Número } \\
\text { de Exames } \\
\text { Realizados por } \\
\text { Grupos de Consumo }\end{array}$ & Direcionador & $\begin{array}{c}\text { Realizar Exames } \\
\text { Contrastados } \\
\text { Alocadosaos } \\
\text { Grupos de Consumo }\end{array}$ & $\begin{array}{l}\text { Custos Agrupados } \\
\text { por Grupos de } \\
\text { Consumo }\end{array}$ \\
\hline 3600 & $R \$ 2.600,91$ & 2223 & $2,3872 \%$ & $\mathrm{R} \$ 5.108,56$ & $\mathrm{R} \$ 7.709,47$ \\
\hline 3600 & $\mathrm{R} \$ 702,26$ & 962 & $1,0331 \%$ & $\mathrm{R} \$ 2.210,72$ & $\mathrm{R} \$ 2.912,98$ \\
\hline 3114 & $\mathrm{R} \$ 74,52$ & 207 & $0,2223 \%$ & $\mathrm{R} \$ 475,70$ & $\mathrm{R} \$ 550,22$ \\
\hline 3010 & $\mathrm{R} \$ 19.472,70$ & 24965 & $26,8089 \%$ & $\mathrm{R} \$ 57.370,80$ & $\mathrm{R} \$ 76.843,50$ \\
\hline 2705 & $\mathrm{R} \$ 7,56$ & 12 & $0,0129 \%$ & $\mathrm{R} \$ 27,58$ & $\mathrm{R} \$ 35,14$ \\
\hline 2400 & $\mathrm{R} \$ 837,27$ & 1329 & $1,4272 \%$ & $\mathrm{R} \$ 3.054,11$ & $\mathrm{R} \$ 3.891,38$ \\
\hline 2160 & $\mathrm{R} \$ 12,22$ & 47 & $0,0505 \%$ & $\mathrm{R} \$ 108,01$ & $\mathrm{R} \$ 120,23$ \\
\hline 1920 & $\mathrm{R} \$ 578,16$ & 1752 & $1,8814 \%$ & $\mathrm{R} \$ 4.026,18$ & $\mathrm{R} \$ 4.604,34$ \\
\hline 1728 & $\mathrm{R} \$ 654,56$ & 4091 & $4,3932 \%$ & $\mathrm{R} \$ 9.401,32$ & $\mathrm{R} \$ 10.055,88$ \\
\hline 1674 & $\mathrm{R} \$ 593,56$ & 3124 & $3,3547 \%$ & $\mathrm{R} \$ 7.179,11$ & $\mathrm{R} \$ 7.772,67$ \\
\hline 1566 & $\mathrm{R} \$ 21,42$ & 238 & $0,2556 \%$ & $\mathrm{R} \$ 546,94$ & $\mathrm{R} \$ 568,36$ \\
\hline 1505 & $\mathrm{R} \$ 2.593,50$ & 7415 & $7,9627 \%$ & $\mathrm{R} \$ 17.040,04$ & $\mathrm{R} \$ 19.633,54$ \\
\hline 1440 & $\mathrm{R} \$ 1.620,54$ & 9003 & $9,6680 \%$ & $\mathrm{R} \$ 20.689,34$ & $\mathrm{R} \$ 22.309,88$ \\
\hline 1296 & $\mathrm{R} \$ 2,70$ & 27 & $0,0290 \%$ & $\mathrm{R} \$ 62,05$ & $\mathrm{R} \$ 64,75$ \\
\hline 1200 & $\mathrm{R} \$ 1.024,08$ & 4267 & $4,5822 \%$ & $\mathrm{R} \$ 9.805,78$ & $\mathrm{R} \$ 10.829,86$ \\
\hline 1170 & $\mathrm{R} \$ 0,12$ & 2 & $0,0021 \%$ & $\mathrm{R} \$ 4,60$ & $\mathrm{R} \$ 4,72$ \\
\hline 1098 & $\mathrm{R} \$ 19,32$ & 276 & $0,2964 \%$ & $\mathrm{R} \$ 634,26$ & $\mathrm{R} \$ 653,58$ \\
\hline 936 & $\mathrm{R} \$ 2,12$ & 53 & $0,0569 \%$ & $\mathrm{R} \$ 121,80$ & $\mathrm{R} \$ 123,92$ \\
\hline 864 & $\mathrm{R} \$ 944,88$ & 13051 & $14,0149 \%$ & $\mathrm{R} \$ 29.991,84$ & $\mathrm{R} \$ 30.936,72$ \\
\hline 720 & $\mathrm{R} \$ 674,28$ & 6757 & $7,2561 \%$ & $\mathrm{R} \$ 15.527,92$ & $\mathrm{R} \$ 16.202,20$ \\
\hline 702 & $\mathrm{R} \$ 239,85$ & 7995 & $8,5855 \%$ & $\mathrm{R} \$ 18.372,90$ & $\mathrm{R} \$ 18.612,75$ \\
\hline 600 & $\mathrm{R} \$ 3,18$ & 53 & $0,0569 \%$ & $\mathrm{R} \$ 121,80$ & $\mathrm{R} \$ 124,98$ \\
\hline 468 & $\mathrm{R} \$ 93,34$ & 4667 & $5,0117 \%$ & $\mathrm{R} \$ 10.725,00$ & $\mathrm{R} \$ 10.818,34$ \\
\hline 432 & $\mathrm{R} \$ 18,18$ & 606 & $0,6508 \%$ & $\mathrm{R} \$ 1.392,62$ & $\mathrm{R} \$ 1.410,80$ \\
\hline Totais & $\mathrm{R} \$ 32.791,23$ & 93122 & $100,00 \%$ & $\mathrm{R} \$ 213.998,95$ & $\mathrm{R} \$ 246.790,18$ \\
\hline
\end{tabular}


A seguir, obteve-se o custo por medida das atividades comuns a todos os objetos, ou seja, as desen- volvidas na recepção, na revelação de filmes, na interpretação de resultados e registro de laudos.

Tabela 6 - Custo Rastreado para as Atividades Comuns aos Objetos de Custo

\begin{tabular}{l|c|c|c|c} 
Atividades & Medida de Saída & Recursos & Direcionador & Custo das Medidas \\
Recepcionar Pacientes & Número de Pacientes & $\mathrm{R} \$ 14.386,22$ & 86.687 & $\mathrm{R} \$ 0,165956$ \\
\hline Revelar Filmes & Número de Incidências & $\mathrm{R} \$ 352.043,59$ & 214.315 & $\mathrm{R} \$ 1,642646$ \\
\hline Interpretar Resultados & Número de Exames & $\mathrm{R} \$ 184.655,82$ & 94.589 & $\mathrm{R} \$ 1,952191$ \\
\hline Registrar Laudos & Número de Laudos & $\mathrm{R} \$ 28.101,22$ & 94.589 & $\mathrm{R} \$ 0,297088$ \\
\hline
\end{tabular}

A soma dessas atividades somou $\mathrm{R} \$ 4,059461$, cujo valor representa o que todos os objetos de custos consumirão por serem necessárias ao processo de produção de imagens radiológicas. Portanto, custo das medidas comuns será acrescentado ao custo das medidas dos exames convencionais e exames contrastados, sendo que, nos últimos, a atividade Recepcionar Pacientes é consumida duas vezes, pois que comparecem para a marcação do exame, quan- do então recebem instruções nutricionais e, para a realização do exame. Portanto, à atividade Realizar Exames Contrastados será acrescida do custo da medida da atividade Recepcionar Pacientes, ou seja, $\mathrm{R} \$ 0,165956$. Os custos das atividades dos objetos de custos, segregados em exames contrastados e exames convencionais, são rastreados para as atividades por grupo de consumo conforme mostram as Tabelas 7 e 8.

Tabela 7 - Custo das Medidas dos Exames Convencionais

\begin{tabular}{|c|c|c|c|}
\hline $\begin{array}{l}\text { Grupos de Consumo de } \\
\text { Filme Radiológico por } \\
\text { Quantidades em } \mathrm{cm}^{2}\end{array}$ & $\begin{array}{c}\text { Custos Agrupados por } \\
\text { Grupos de Consumo }\end{array}$ & $\begin{array}{l}\text { Número de Exames } \\
\text { Realizados por } \\
\text { Grupos de Consumo }\end{array}$ & Custo das Medidas \\
\hline 4515 & $\mathrm{R} \$ 7.709,47$ & 2223 & $R \$ 3,47$ \\
\hline 3600 & $\mathrm{R} \$ 2.912,98$ & 962 & $\mathrm{R} \$ 3,03$ \\
\hline 3114 & $\mathrm{R} \$ 550,22$ & 207 & $\mathrm{R} \$ 2,66$ \\
\hline 3010 & $\mathrm{R} \$ 76.843,50$ & 24965 & $\mathrm{R} \$ 3,08$ \\
\hline 2705 & $\mathrm{R} \$ 35,14$ & 12 & $\mathrm{R} \$ 2,93$ \\
\hline 2400 & $\mathrm{R} \$ 3.891,38$ & 1329 & $\mathrm{R} \$ 2,93$ \\
\hline 2160 & $\mathrm{R} \$ 120,23$ & 47 & $\mathrm{R} \$ 2,56$ \\
\hline 1920 & $\mathrm{R} \$ 4.604,34$ & 1752 & $\mathrm{R} \$ 2,63$ \\
\hline 1728 & $\mathrm{R} \$ 10.055,88$ & 4091 & $\mathrm{R} \$ 2,46$ \\
\hline 1674 & $\mathrm{R} \$ 7.772,67$ & 3124 & $R \$ 2,49$ \\
\hline 1566 & $\mathrm{R} \$ 568,36$ & 238 & $\mathrm{R} \$ 2,39$ \\
\hline 1505 & $\mathrm{R} \$ 19.633,54$ & 7415 & $\mathrm{R} \$ 2,65$ \\
\hline 1440 & $\mathrm{R} \$ 22.309,88$ & 9003 & $R \$ 2,48$ \\
\hline 1296 & $\mathrm{R} \$ 64,75$ & 27 & $\mathrm{R} \$ 2,40$ \\
\hline 1200 & $\mathrm{R} \$ 10.829,86$ & 4267 & $\mathrm{R} \$ 2,54$ \\
\hline 1170 & $\mathrm{R} \$ 4,72$ & 2 & $\mathrm{R} \$ 2,36$ \\
\hline 1098 & $\mathrm{R} \$ 653,58$ & 276 & $\mathrm{R} \$ 2,37$ \\
\hline 936 & $R \$ 123,92$ & 53 & $R \$ 2,34$ \\
\hline 864 & $\mathrm{R} \$ 30.936,72$ & 13051 & $\mathrm{R} \$ 2,37$ \\
\hline 720 & $\mathrm{R} \$ 16.202,20$ & 6757 & $\mathrm{R} \$ 2,40$ \\
\hline 702 & $\mathrm{R} \$ 18.612,75$ & 7995 & $\mathrm{R} \$ 2,33$ \\
\hline 600 & $\mathrm{R} \$ 124,98$ & 53 & $\mathrm{R} \$ 2,36$ \\
\hline 468 & $\mathrm{R} \$ 10.818,34$ & 4667 & $R \$ 2,32$ \\
\hline 432 & $\mathrm{R} \$ 1.410,80$ & 606 & $\mathrm{R} \$ 2,33$ \\
\hline Totais & R\$ 246.790,21 & 93122 & - \\
\hline
\end{tabular}


Tabela 8 - Custo das Medidas dos Exames Contrastados

\begin{tabular}{c|c|c|c}
\hline $\begin{array}{c}\text { Grupos de Consumo de } \\
\begin{array}{c}\text { Filme Radiológico por } \\
\text { Quantidades em } \mathbf{~ m}^{2}\end{array}\end{array}$ & $\begin{array}{c}\text { Nustos Segregados por } \\
\text { Grupos de Atributos } \\
10340\end{array}$ & $\begin{array}{c}\text { Realizados por } \\
\text { Grupos de Atributos }\end{array}$ & Custo das Medidas \\
\hline 7525 & $\mathrm{R} \$ 4.341,64$ & 500 & $\mathrm{R} \$ 8,68$ \\
\hline 6000 & $\mathrm{R} \$ 25,63$ & 3 & $\mathrm{R} \$ 8,54$ \\
\hline 5472 & $\mathrm{R} \$ 359,41$ & 46 & $\mathrm{R} \$ 7,81$ \\
\hline 5170 & $\mathrm{R} \$ 3.117,24$ & $\mathrm{R} \$ 7,13$ \\
\hline 4560 & $\mathrm{R} \$ 328,23$ & $\mathrm{R} \$ 7,63$ \\
\hline 4385 & $\mathrm{R} \$ 682,93$ & $\mathrm{R} \$ 7,34$ \\
\hline 3010 & $\mathrm{R} \$ 7,33$ & $\mathrm{R} \$ 7,33$ \\
\hline 2250 & $\mathrm{R} \$ 1.260,81$ & $\mathrm{R} \$ 7,37$ \\
\hline 2160 & $\mathrm{R} \$ 6,78$ & $\mathrm{R} \$ 6,78$ \\
\hline 2105 & $\mathrm{R} \$ 678,47$ & 1 & $\mathrm{R} \$ 6,85$ \\
\hline 1566 & $\mathrm{R} \$ \mathbf{7 , 0 4}$ & 171 & $\mathrm{R} \$ 7,04$ \\
\hline Totais & $\mathrm{R} \$ 481,20$ & 1 & $\mathrm{R} \$ 6,68$ \\
\hline
\end{tabular}

O trabalho, até então, possui o custo das medidas das atividades comuns a todos os objetos de custos, e o custo das atividades de realizar exames convencionais e contrastados, segundo os atributos de consumo de filmes radiológicos, agrupados por consumo dessa matéria-prima.

A seguir, o custo de cada medida é rastreado para os objetos de custos, por grupos de consumo, aos exames contrastados e convencionais, conforme mostram as Tabelas 9 e 10.

\section{Tabela 9 - Custo das Atividades dos Exames Contrastados}

\begin{tabular}{|c|c|c|c|c|c|}
\hline Exame Radiológico & $\begin{array}{l}\text { Atributos de } \\
\text { Consumo } \\
\text { em } \mathrm{cm}^{2}\end{array}$ & $\begin{array}{l}\text { Custo das } \\
\text { Medidas } \\
\text { do Grupo }\end{array}$ & $\begin{array}{l}\text { Custo das } \\
\text { Atividades } \\
\text { Comuns }\end{array}$ & $\begin{array}{c}\text { Custo da } \\
\text { Atividade } \\
\text { Recepcionar } \\
\text { Pacientes }\end{array}$ & $\begin{array}{l}\text { Custo das } \\
\text { Atividades }\end{array}$ \\
\hline \multicolumn{6}{|l|}{$\begin{array}{l}\text {-Clister Opaco } \\
\text {-Clister Opaco com Duplo Contraste } \\
\text {-Urografia Venosa da Bexiga - Pré e Pós Micção } \\
\text {-Urografia Venosa com Dripping ou Macrose } \\
\text {-Urografia Venosa com Nefrotomografias }\end{array}$} \\
\hline -Urografia Minutada 1-2-3 & 10.340 & $\mathrm{R} \$ 8,68$ & $\mathrm{R} \$ 4,059461$ & $\mathrm{R} \$ 0,165956$ & $\mathrm{R} \$ 12,90$ \\
\hline -Arteriografia Cérvico Torácica & 7.525 & $\mathrm{R} \$ 8,54$ & $\mathrm{R} \$ 4,059461$ & $\mathrm{R} \$ 0,165956$ & $\mathrm{R} \$ 12,76$ \\
\hline $\begin{array}{l}\text {-Arteriografia do Membro Inferior } \\
\text {-Arteriografia do Membro Inferior Unilateral } \\
\text {-Arteriografia do Membro Superior }\end{array}$ & & & & & \\
\hline -Arteriografia Seletiva Femoral & 6.000 & $\mathrm{R} \$ 7,81$ & $\mathrm{R} \$ 4,059461$ & $\mathrm{R} \$ 0,165956$ & $\mathrm{R} \$ 12,03$ \\
\hline -Trânsito e Morfologia do Delgado & 5.472 & $\mathrm{R} \$ 7,13$ & $\mathrm{R} \$ 4,059461$ & $\mathrm{R} \$ 0,165956$ & $\mathrm{R} \$ 11,35$ \\
\hline $\begin{array}{l}\text { - Coração e Vasos da Base Posterior, Anterior, } \\
\text { Lateral e Oblíquas }\end{array}$ & & & & & \\
\hline -Coração e Vasos da Base Posterior, Anterior e Lateral & 5.170 & $\mathrm{R} \$ 7,63$ & $\mathrm{R} \$ 4,059461$ & $\mathrm{R} \$ 0,165956$ & $\mathrm{R} \$ 11,85$ \\
\hline -Uretrocistografia & 4.560 & $\mathrm{R} \$ 7,34$ & $\mathrm{R} \$ 4,059461$ & $\mathrm{R} \$ 0,165956$ & $\mathrm{R} \$ 11,56$ \\
\hline -Urografia Venosa & 4.385 & $\mathrm{R} \$ 7,33$ & $\mathrm{R} \$ 4,059461$ & $\mathrm{R} \$ 0,165956$ & $\mathrm{R} \$ 11,55$ \\
\hline -Esôfago, Estômago, Duodeno e Hiato Diafragmático & 3.010 & $\mathrm{R} \$ 7,37$ & $\mathrm{R} \$ 4,059461$ & $\mathrm{R} \$ 0,165956$ & $\mathrm{R} \$ 11,59$ \\
\hline -RCVB-Coração e Vasos da Base & 2.250 & $\mathrm{R} \$ 6,78$ & $\mathrm{R} \$ 4,059461$ & $\mathrm{R} \$ 0,165956$ & $\mathrm{R} \$ 11,00$ \\
\hline
\end{tabular}

-Coleangeografia Per Operatória

-Coleangeografia Pós Operatória

-Coleangeografia Pré Operatória

-Coleangeografia Transcutânea

-Coleangeografia Venosa-Esôfago

-Fistulografia

2.160

-Colecistograma Ora

-Artrografia
2.105

1.566
$\mathrm{R} \$ 6,85$

$\mathrm{R} \$ 7,04$

$\mathrm{R} \$ 6,68$
$R \$ 4,059461$

$\mathrm{R} \$ 4,059461$

$\mathrm{R} \$ 4,059461$
$R \$ 0,165956$

$\mathrm{R} \$ 0,165956$

$\mathrm{R} \$ 0,165956$
$\mathrm{R} \$ 11,07$

$\mathrm{R} \$ 11,26$

$\mathrm{R} \$ 10,90$

Revista Contabilidade \& Finanças - USP, São Paulo, n. 34, p. 63 - 79, janeiro/abril 2004 
O custeio das atividades para a realização dos exames convencionais segue a mesma sistemática, diferenciando-se dos anteriores no que concerne ao número de vezes que consome a atividade Recepcionar Pacientes, ou seja, somente uma vez como mostrado na Tab. 10.

\section{Tabela 10 - Custo das Atividades dos Exames Convencionais}

\begin{tabular}{|c|c|c|c|c|}
\hline Exame Radiológico & $\begin{array}{l}\text { Atributos de } \\
\text { Consumo } \\
\text { em } \mathrm{cm}^{2}\end{array}$ & $\begin{array}{l}\text { Custo das } \\
\text { Medidas } \\
\text { do Grupo }\end{array}$ & $\begin{array}{l}\text { Custo das } \\
\text { Atividades } \\
\text { comuns }\end{array}$ & $\begin{array}{l}\text { Custo das } \\
\text { Atividades }\end{array}$ \\
\hline -Abdômen Agudo-Abdômen Total & 4.515 & $\mathrm{R} \$ 3,47$ & $\mathrm{R} \$ 4,059461$ & $\mathrm{R} \$ 7,52$ \\
\hline -Coluna Dorso Lombar para Escoliose & & & & \\
\hline -Crânio Posterior, Anterior, Lateral e Bretton & 3.600 & $R \$ 3,03$ & $R \$ 4,059461$ & $\mathrm{R} \$ 7,08$ \\
\hline $\begin{array}{l}\text {-Coluna Lombo Sacra com Oblíquas e Seletivas } \\
\text {-Coluna Lombo Sacra com Oblíquas }\end{array}$ & & & & \\
\hline -Coluna Lombo Sacra Funcional ou Dinâmica & 3.114 & $R \$ 2,66$ & $R \$ 4,059461$ & $\mathrm{R} \$ 6,71$ \\
\hline $\begin{array}{l}\text {-Tórax Extra Cardíaco-Tórax Posterior, Anterior, Lateral } \\
\text { e Oblíquas-Tórax RCP }\end{array}$ & & & & \\
\hline -Tórax Lordótica-Tórax Posterior, Anterior e Lateral & 3.010 & $R \$ 3,08$ & $R \$ 4,059461$ & $\mathrm{R} \$ 7,13$ \\
\hline -Tórax Posterior, Anterior com inspiração, expiração e Lateral & 2.705 & $\mathrm{R} \$ 2,93$ & $\mathrm{R} \$ 4,059461$ & $\mathrm{R} \$ 6,98$ \\
\hline -Coluna Dorsal-Coluna Dorsal Anterior, Posterior e Lateral & 2.400 & $\mathrm{R} \$ 2,93$ & $\mathrm{R} \$ 4,059461$ & $\mathrm{R} \$ 6,98$ \\
\hline $\begin{array}{l}\text {-Crânio-Crânio Posterior, Anterior, Lateral, Oblíquas } \\
\text { ou Lateral Bretton }\end{array}$ & & & & \\
\hline -Hirtz-Mediastino-Mediastino Posterior, Anterior e Perfil & 2.160 & $R \$ 2,56$ & $\mathrm{R} \$ 4,059461$ & $\mathrm{R} \$ 6,61$ \\
\hline -Arcos Costais - um lado & & & & \\
\hline -Costela por Hemotórax & 1.920 & $R \$ 2,63$ & $\mathrm{R} \$ 4,059461$ & $\mathrm{R} \$ 6,68$ \\
\hline $\begin{array}{l}\text {-Coluna Cervical e Oblíquas } \\
\text {-Coluna } \\
\text { Cervical Anterior, Posterior, Lateral, Transoblíquas e Oblíquas } \\
\text {-Mastóides ou Rochedos Bilateral } \\
\text {-Ossos da Face MN, Lateral e Hirtz } \\
\text {-Coluna Cervical Funcional ou Dinâmica }\end{array}$ & & & & \\
\hline -Ossos da Face MN, FN, Lateral e Hirtz & 1.728 & $R \$ 2,46$ & $\mathrm{R} \$ 4,059461$ & \\
\hline -Coluna Lombo Sacra & 1.674 & $\mathrm{R} \$ 2,49$ & $\mathrm{R} \$ 4,059461$ & $\mathrm{R} \$ 6,54$ \\
\hline -Joelho ou Rótula Anterior, Posterior, Lateral, Oblíquas e 3 Axiais & 1.566 & $\mathrm{R} \$ 2,39$ & $\mathrm{R} \$ 4,059461$ & $\mathrm{R} \$ 6,44$ \\
\hline $\begin{array}{l}\text {-Abdômen Simples } \\
\text {-Abdômen Simples, } \\
\text { Anterior e Posterior } \\
\text {-Escanometria }\end{array}$ & & & & \\
\hline -Tórax Posterior e Anterior & 1.505 & $R \$ 2,65$ & $\mathrm{R} \$ 4,059461$ & $\mathrm{R} \$ 6,70$ \\
\hline
\end{tabular}

-Articulação Coxo Femoral (cada lado)

-Articulação coxo Femoral

-Crânio Posterior, Anterior e Lateral

-Esterno

-Mão ou Quirodáctilos

-Mão(duas incidências)

-Transição Dorso Lombar

1.440

$R \$ 2,48 \quad R \$ 4,059461$

$R \$ 6,53$

-Coluna Cervical

-Maxilar Inferior, Posterior, Anterior e Oblíquas

-Órbitas Posterior, Anterior, Oblíquas e Hirtz

-Bacia

-Braço

-Coxa

1.170

$\mathrm{R} \$ 2,54$

$R \$ 2,40$

$R \$ 4,059461$

$\mathrm{R} \$ 6,45$

- Condutos Auditivos Internos

$\mathrm{R} \$ 2,36$

$\mathrm{R} \$ 4,059461$

$\mathrm{R} \$ 6,59$

-Joelhos Anterior, Posterior, Lateral,

Oblíquas e 3 Axiais

-Joelho com Axial e Rótula

-Joelho ou Rótula Anterior, Posterior, Lateral e Axial

-Articulação Têmporo Mandibular Lateral

\begin{tabular}{cccc}
1.098 & $\mathrm{R} \$ 2,37$ & $\mathrm{R} \$ 4,059461$ & $\mathrm{R} \$ 6,42$ \\
\hline 936 & $\mathrm{R} \$ 2,34$ & $\mathrm{R} \$ 4,059461$ & $\mathrm{R} \$ 6,39$ \\
\hline
\end{tabular}


Tabela 10 - Custo das Atividades dos Exames Convencionais

\begin{tabular}{|c|c|c|c|c|}
\hline Exame Radiológico & $\begin{array}{l}\text { Atributos de } \\
\text { Consumo } \\
\text { em } \mathrm{cm}^{2}\end{array}$ & $\begin{array}{l}\text { Custo das } \\
\text { Medidas } \\
\text { do Grupo }\end{array}$ & $\begin{array}{c}\text { Custo das } \\
\text { Atividades } \\
\text { comuns }\end{array}$ & $\begin{array}{l}\text { Custo das } \\
\text { Atividades }\end{array}$ \\
\hline $\begin{array}{l}\text {-Articulação Escápulo Umeral } \\
\text {-Articulação Externo Clavicular } \\
\text {-Articulação Escápulo Umeral(ombro) } \\
\text {-Articulação Sacro llíacas } \\
\text {-Cavum Lateral e Hirtz } \\
\text {-Cavum ou Rinofaringe Coluna Sacro Cóccis } \\
\text {-Crânio e Towne } \\
\text {-Hipofaringe } \\
\text {-Joelho Anterior, Posterior e Lateral } \\
\text {-Joelho Simples } \\
\text {-Laringe } \\
\text {-Mãos e Punhos para Idade Óssea } \\
\text {-Omoplata Funcional } \\
\text {-Omoplata }\end{array}$ & & & $\mathrm{R} \$ 4059461$ & \\
\hline $\begin{array}{l}\text {-Sacro Cóccis } \\
\text {-Pé ou Pododáctilos }\end{array}$ & 864 & $\mathrm{R} \$ 2,37$ & $\mathrm{R} \$ 4,059461$ & $\mathrm{R} \$ 6,42$ \\
\hline -Perna & 720 & $\mathrm{R} \$ 2,40$ & $\mathrm{R} \$ 4,059461$ & $\mathrm{R} \$ 6,45$ \\
\hline $\begin{array}{l}\text {-Punho anterior, Posterior, Lateral e Oblíquas } \\
\text {-Seios da Face }\end{array}$ & & & & \\
\hline -Seios da Face FN, MN e Lateral & 702 & $R \$ 2,33$ & $\mathrm{R} \$ 4,059461$ & $\mathrm{R} \$ 6,38$ \\
\hline -Articulação Acrômio Clavicular & 600 & $\mathrm{R} \$ 2,36$ & $\mathrm{R} \$ 4,059461$ & $\mathrm{R} \$ 6,41$ \\
\hline $\begin{array}{l}\text {-Antebraço } \\
\text {-Arcada Zigomática e Malar } \\
\text {-Estilóides Anterior, Posterior e Oblíquas } \\
\text {-Arcos Zigomáticos Malar } \\
\text {-Estilóides Anterior, Posterior e Oblíquas } \\
\text {-Articulação Tíbio Társica } \\
\text {-Calcâneo } \\
\text {-Cotovelo } \\
\text {-Seios da Face FN, MN, Lateral e Hirtz } \\
\text {-Sela Túrsida Anterior, Posterior, Lateral e Bretton }\end{array}$ & & & & \\
\hline -Punho & 468 & $\mathrm{R} \$ 2,32$ & $\mathrm{R} \$ 4,059461$ & $\mathrm{R} \$ 6,37$ \\
\hline -Clavícula & 432 & $\mathrm{R} \$ 2,33$ & $\mathrm{R} \$ 4,059461$ & $\mathrm{R} \$ 6,38$ \\
\hline
\end{tabular}

\section{CONCLUSÃO}

O crescimento das organizações de saúde suplementar nacionais e estrangeiras aumenta continuamente o nível competitivo entre elas, impelindo-as a transferir custos operacionais para os hospitais.

Essa transferência de eficiência se dá pela intenção dos gestores de empresas de saúde privadas em manterem-se saudáveis financeiramente e, assim, projetam a obtenção de vantagem nos custos, pressionando, dessa forma, os gestores das instituições de atenção à saúde no sentido de minimizarem os repasses a essas pelos serviços prestados.

Diante desse painel, a aplicação do ABC num setor específico de um hospital constitue-se em um ensaio útil pela visão pormenorizada das atividades que esse método de custeio dá aos gestores, e pela possibilidade de disporem de informações de alto nível de acurácia acerca dos exames radiológicos.

A questão de pesquisa do trabalho limitou-se, preliminarmente, em determinar o custo unitário dos exames radiológicos. Durante o desenvolvimento do trabalho, entretanto, obteve-se o quantum de recursos que foram consumidos pelos objetos, agrupados em exames radiológicos convencionais e contrastados.

Essa divisão contemplou as características de cada grupo de exames, o que, em última instância, superou o problema a ser pesquisado. Portanto, essa visão oferecerá ao gestor comparar a lucratividade de cada grupo de exames e estabelecer parâmetros de retorno quando das negociações de pacotes de serviços ou procedimentos 
médico-hospitalares específicos com as organizações atuantes na saúde suplementar, considerando as especificidades de cada exame.

A pesquisa percentualizou o consumo de recursos pelas atividades em relação ao custo de cada um. A apli- cação desse percentual permitirá aos gestores obter o consumo efetivo de recursos por grupo de exames e, quando confrontada essa informação com o custo da matéria-prima acrescida dos demais custos, determinar o nível de lucro de cada objeto.

\section{REFERÊNCIAS BIBLIOGRÁFICAS}

CHING, Hong Yuh. Gestão baseada em custeio por atividades: (ABM) - activity based management. 3. ed. São Paulo: Atlas, 2001. $176 \mathrm{p}$.

Manual de custos de instituições de saúde: sistemas tradicionais de custos e sistema de custeio baseado em atividades (ABC). São Paulo: Atlas, 2001. 233 p.

FALK, James Anthony. Gestão de custos para hospitais: conceitos, metodologias e aplicações. São Paulo: Atlas, 2001. $163 \mathrm{p}$.

HOPPEN, N.; LAPOINTE, L.; MOREAU, E. Um guia para avaliação de artigos de pesquisa em sistemas de informação. Coleção para Estudo, PPGA/UFRGS, 1996.

HORNGREN, Charles T.; FOSTER, George; DATAR, Srikant. Contabilidade de custos. 9. ed. Rio de Janeiro: LTC, 2000. 717 p.

MARTINS, Eliseu. Contabilidade de custos - inclui o ABC. 8. ed. São Paulo: Atlas, 2001. 388 p.

ANDERSON, Shannon W., YOUNG, S. mark. The impact of contextual and process factors on the evaluation of activitybased costing system. Accounting, Organization and Society, 1999. v. 24, p. 525-559.

BACIC, Miguel Juran. Escopo da gestão estratégica de custos e, face de noções de competitividade e de estratégia empresarial. Io Congresso Brasileiro de Gestão Estratégica de Custos[Anais]. São Leopoldo, p. 295-304, 1994.

BARROS, Aidil de Jesus Paes de. Projeto de pesquisa: propostas metodológicas. Petrópolis, RJ: Vozes, 1990. 127 p.

BEULKE, Rolando; BERTO, Dalvio José. Gestão de custos e resultado na saúde: hospitais, clínicas, laboratórios e congêneres. 1 ed. São Paulo: Saraiva, 1997. 192p.

BEUREN, Ilse Maria; OLIVEIRA, Hilamar Voigt. Mensuração das atividades empresariais: custeio baseado em atividades $\mathrm{x}$ método da unidade de esforço de produção. Revista CRCRS № 84. Porto Alegre: 1996.

BORENSTEIN, Denis; SCHMIDT, Paulo. Determinação de direcionadores múltiplos de custos das atividades: o caso DMLU - Prefeitura de Porto Alegre. In: VII Congresso Brasileiro de Custos[Anais]. Recife, 2000.

NOTA:

Endereço do autor:

SIMEÃO ANTÔNIO SILVEIRA BRASIL

Centro Universitário La Salle

Av. Victor Barreto, 2288

Canos - RS

92010-000
MARTINS, Domingos dos Santos. Custeio hospitalar por atividades: activity based costing. São Paulo: Atlas, 2002. 170 p.

NAKAGAWA, Masayuki. ABC -custeio baseado em atividades.

Gestão estratégica de custos. São Paulo: Atlas, 2000. 111 p.

SCHMIDT, P.(org). Controladoria - agregando valor para a empresa. Porto Alegre: Bookman, 2002. 262 p.

Gestão estratégica de custos. Apostila de aula do Curso de Mestrado Profissional em Economia com ênfase em controladoria. UFRGS. [s.n.]. Porto Alegre, 2002.

TOBAR, Frederico; YALOUR, Margot R. Como fazer teses em saúde pública: conselhos e idéias para formular projetos e redigir teses e informes de pesquisas. Rio de Janeiro: Ed. Fiocruz, 2001. 172 p.

WEYGANDT, Jerry J., KIESO, Donald E. \& KIMMEL, Paul D. Managerial accounting. N.Y., John Wiley \& Sons, Inc. 2002.

BIBLIOGRAFIA COMPLEMENTAR

CAPASSO, Carmelo et al. Custeio baseado em atividades (ABC) vs métodos tradicionais de custeio. Revista Brasileira de Contabilidade no 116, mar/abr, P. 72-81, 1999.

CHIAVENATO, Idalberto. Teoria geral da administração. 2. ed. São Paulo: MacGraw Hill, 1999. 710 p.

DOUGLAS C.; MARINUS J. B. The association between activity-based costing and improvement in financial performance. Management Accounting Reseach n. 13. p. 1-39. Disponível em <http://www.ideallibrary.com.on>. Acesso em 18 janeiro. 2003.

EASTMAN KODAK COMPANY. Fundamentos de radiologia. [s.I.:s.n.], 1980.

SAKURAI, Michiharu \& ROCCHI, Carlos Antônio (Trad.). Custeamento-meta e como utilizá-lo. Revista do Conselho Regional de Contabilidade do Rio Grande do Sul n. 94, P.2235, out. 1998.

WILLSON, James D., ROEHL-ANDERSON, Janice M. \& BRAGG, Steven M. Controllership - the work of the managerial accounting. 5. ed., New York: John Wiley \& Sons, Inc., 1998. 1777 p.

YIN, Robert K. Estudo de caso: planejamento e métodos. 2 ed. Porto Alegre: Bookman, 2001. 205 p. 2. ed. São Paulo: Atlas, 2001.95 p. 